3. To whom should practitioners should report adverse drug reaction?
a. RCVS
b. VMD
c. BSAVA
d. BVA

4. Which drug is an inducer of cytochrome P450?
a. Cimetidine
b. Phenobarbital
c. Metronidazole
d. Ketoconazole

5. Which statement is the most appropriate with regard to pharmacodynamic interactions?

a. Occurs when one drug directly affects the metabolism of another drug

b. Occurs when one drug directly affects the excretion of another drug

c. Occurs exclusively when more than one drug acts at the same target receptor

d. Occurs when one drug affects the pharmacological action of another drug at the target receptor or system level

\section{The VDS top ten causes for claims against vets}

\section{Stuart Ellis and Michael Stanford}

The Veterinary Defence Society (VDS) is a mutual insurance company run by experienced veterinary surgeons, which insures the vast majority of the practising veterinary profession against the effects of claims of negligence. 150 years old this year, the VDS ensures that cases are handled by veterinary colleagues experienced in claims management, defends reputations and finances against unjustified claims and offers compensation when appropriate. The VDS policy includes cover for negligence resulting in human injury, and provides legal representation at criminal and disciplinary hearings. Advice and guidance is also provided to members.

Now that many practices outsource their out-of-hours provision, the days of sorting out postoperative complications, such as haemorrhage or wound breakdown, 'in-house' are fast disappearing. If these events occur as a result simply of misfortune rather than negligence, then who pays?

Since the advent of the Pet Travel Scheme the Society has handled a steady stream of claims related to clerical errors in passports or advice provided to pet owners preparing to travel, and changes to the regulations by DEFRA continue to catch many practitioners unawares.

Medicines information is now freely available to any client with access to the internet and the pharmacy remains a place where inadvertent prescribing and dispensing errors can easily be made.

Although the term negligence is used extensively, in reality the bar for successfully bringing a claim in professional negligence is set high. This reflects the fact the legal system understands the well recognised difficulties of working with biological systems and appreciates clinicians can employ entirely different approaches to the same problem, equally successfully. Negligence claims are ultimately determined in the civil courts by a judge who will rely on expert evidence provided by an independent veterinary surgeon or nurse. The essential principle, relied upon by the Court in professional negligence is 'did the professional approach the case in a manner in accordance with a reasonable body of their peers?' This is known as the Bolam principal.

You will always be judged by what is considered a reasonable course of action by your peers, irrespective of the outcome of the clinical case, and if you follow standard recognised techniques used by a reasonable body of the profession, it is unlikely you could ever be found negligent. If liability is accepted for a negligent act, for compensation to be due the claimant still has to demonstrate a genuine financial loss. Damages for distress are not payable under UK law in respect of an animal, as they are considered chattels legally, even pets. Negligence claims are not directed against an individual, but a business. Even with a successful claim it would ultimately be the business, or their insurer, settling any claim for damages.

To reduce the risk of negligence claims it is important to stay up to date by carrying out at least the prerequisite quota of CPD (presently 105 hours for veterinary surgeons, 45 for nurses over 3 years) which ensures you remain competent and aware of the standards of a reasonable body of your peers.

You should also be able to demonstrate that you have informed, warned and gained consent from clients, preferably in writing. It is also advisable to keep good contemporaneous notes which can subsequently be used to defend your position. As many claims are associated with postoperative care, it is important to provide all advice in writing to clients.

\section{KEY LEARNING OBJECTIVES}

- Be more aware of the common pitfalls in everyday practice that may lead to negligence claims

- Be able to recognise when things have gone wrong and who to turn to for help

- Be better prepared to handle potential claimants in a professional manner without compromising their own position or that of their indemnity insurer 